\title{
Effects of chitosan addition on growth performance, diarrhoea, anti-oxidative function and serum immune parameters of weaned piglets
}

\author{
Y. Q. Xu, Z .Q. Wang, Z. Qin, S. M. Yan \& B. L. Shi ${ }^{\#}$ \\ College of Animal Science, Inner Mongolia Agricultural University, 306 Zhaowuda Road, Hohhot 010018, Inner Mongolia, \\ China
}

(Received 22 September 2017; Accepted 23 October 2017; First published online 22 November 2017)

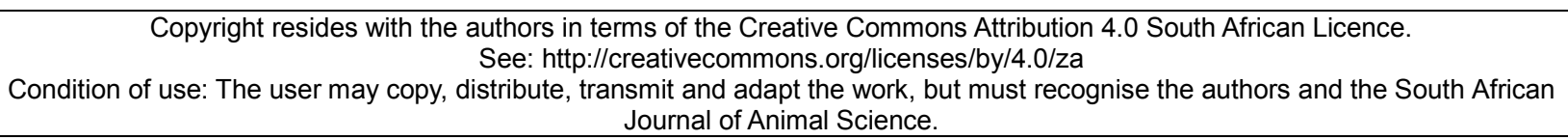

\begin{abstract}
The present experiment was designed to determine the efficacy of a commercial source of chitosan (CS) to enhance performance, anti-oxidative function, and immune response in weaned pigs. A total of 60 crossbreed piglets (Duroc $\times$ Landrace $\times$ Yorkshire), with average live bodyweight of $8.85 \pm 1.52 \mathrm{~kg}$, were weaned at $28 \pm 2$ days and randomly assigned to five treatment groups, which were fed maize-soybean meal diets containing 0 (basal diet, control) and 250, 500, 1000, and $2000 \mathrm{mg} / \mathrm{kg} \mathrm{CS}$. The experiment lasted for two weeks. Body weight was recorded and daily feed intake was calculated. Faecal consistency was monitored for the overall period. After two weeks, blood samples were collected and anti-oxidative and immune parameters were determined. The results showed that CS improved average daily gain and daily gain: daily feed intake during the experiment. Mean faecal score values for the second week were improved by CS, which showed decreased values compared with the control diet. The CS increased the total antioxidant capacity and the activities of superoxide dismutase, catalase and glutathione peroxidase and the content of reduced glutathione in serum, and decreased the malondialdehyde and cortisol contents of serum. Furthermore, CS increased the levels of serum IL-1 $\beta$, IL-2 and IgG. These findings suggested that the use of CS improved performance and anti-oxidative function, and regulated the immune response of weaned pigs.
\end{abstract}

Keywords: Anti-oxidative capability, chitosan, immunity, performance, piglets

\#Corresponding author: shibinlin@yeah.net

\section{Introduction}

Weaning, during which piglets are subjected to abrupt changes in environment, behaviour and diet, is one of the most stressful events in a pig's life. It can contribute to gastrointestinal disorders (Wijtten et al., 2011), immune system dysfunctions (Kick et al., 2012), and endocrine system imbalance (Zhu et al., 2012), and may cause diarrhoea, increased susceptibility to disease, morbidity, and mortality (Madec et al., 2000; Fairbrother et al., 2005), and inhibited growth and health. Weaning therefore causes serious economic losses in pig production worldwide. Additionally, a recent study demonstrated that weaning could induce oxidative stress, resulting in oxidative damage in pigs (Zhu et al., 2012).

Reducing post-weaning stress is one of the main challenges for the pig industry. In traditional commercial practice, the use of additives has been recommended as a way to ameliorate or relieve postweaning stress during this stage. Among them, CS has been indicated as having positive effects on pig growth and health. CS is obtained by deacetylation of chitin, which is present in exoskeletons of arthropods such as crustaceans and insects, and in the outer cell wall of fungi (Jayakumar et al., 2010; Dash et al., 2011). Compared with other natural polysaccharides, a plethora of applications of this biopolymer have been found owing to its high biocompatible, biodegradable, and nontoxic nature (Jayakumar et al., 2010; Dash et al., 2011).As a natural cationic polysaccharide, CS contains reactive functional groups, that is, hydroxyl and amino groups. Numerous studies have demonstrated that CS has unique biological activities, which include anti-microbial (Zheng \& Zhu, 2003), immunostimulatory (Zaharoff et al., 2007), anti-inflammatory (Villiers et al., 2009), anti-tumour (Qin et al., 2002), anti-hypertension (Park et al., 2009), hypocholesterolemic (Liu et al., 2008), anti-obesity (Walsh et al., 2013), and anti-oxidation (Kim \& Thomas, 2007) properties. Notably, because of these properties, CS can be used as a pro-growth and health feed supplement for farm animals. 
However, the causal link between CS and the improvement in pig health status remains largely unknown. Hence, further clarification is necessary.

Accordingly, the main objective of this work was to investigate the effects of CS on anti-oxidative function and immune response in weaned pigs. These findings may be useful in elucidating mechanisms that promote growth and health through enhanced anti-oxidative and immune functions in animals that receive dietary supplementation with CS.

\section{Materials and methods}

The experiment was carried out in the Experimental Farms of Inner Mongolia Agricultural University in China and received prior approval from the Institutional Animal Care and Use Committee of this Institution.

The experiment followed a randomized block design. A total of 60 healthy weaned pigs (Duroc $\times$ Yorkshire $\times$ Landrace, 30 barrows and 30 gilts) from 12 litters (five pigs per litter) were selected from a commercial herd. The animals were weaned at the age of 28 days with average initial bodyweight of 8.85 ( \pm $1.52) \mathrm{kg}$. The animals were randomly assigned to five treatments ( $n=12$, six barrows and six gilts), and were housed in 60 pens (one pig per pen) taking initial body weight and litter (one pig from each litter per treatment) into account. The dietary treatments consisted of a basal diet (control treatment) that was formulated to meet the nutrient requirements of the National Research Council (2012). The compositions are shown in Table 1.Treatments 2-5 consisted of the basal diet supplemented with 250, 5001000 and $2000 \mathrm{mg}$ $\mathrm{CS} / \mathrm{kg}$. No medication or other additives were included in the diets. Throughout the experimental period, animals were allowed access to feed and water ad libitum and exposed to natural lighting.

Table 1 Composition and chemical analysis of basal experimental diets (air dry basis)

\begin{tabular}{lclc}
\hline Ingredients & Content & Nutrient levels & Content \\
\hline & & & \\
Maize & 60.09 & Digestive energy $(\mathrm{MJ} / \mathrm{kg})$ & 13.94 \\
Soybean meal & 26.57 & Crude protein $(\mathrm{N} \times 6.25)$ & 20.37 \\
Wheat bran & 5.00 & Lysine & 1.45 \\
Fish meal & 3.00 & Methionine & 0.47 \\
Soybean oil & 1.00 & Methionine + cysteine & 0.87 \\
Limestone & 1.39 & Threonine & 0.96 \\
Dicalcium phosphate & 0.89 & Tryptophan & 0.24 \\
Salt & 0.30 & Calcium & 0.90 \\
L-Lysine HCL & 0.45 & Phosphorus & 0.61 \\
DL-Methionine & 0.16 & & \\
L-Threonine & 0.15 & & \\
Vitamin/mineral premix & 1.00 & & \\
Total & 100.00 & &
\end{tabular}

\footnotetext{
${ }^{1}$ The premix provided per $\mathrm{kg}$ of diet: vitamin $\mathrm{A}, 8,000 \mathrm{IU}$; vitamin $\mathrm{D}_{3}, 2,000 \mathrm{IU}$; vitamin $\mathrm{E}, 34 \mathrm{mg}$; vitamin $\mathrm{K}_{3}, 2.8 \mathrm{mg}$; vitamin $B_{1}, 2.6 \mathrm{mg}$; vitamin $B_{2} 6.0 \mathrm{mg}$; vitamin $B_{6}, 7.0 \mathrm{mg}$; vitamin $B_{12}, 0.02 \mathrm{mg}$; pantothenic acid, $12 \mathrm{mg}$; nicotinic acid, 50 $\mathrm{mg}$; biotin, $0.47 \mathrm{mg}$; folic acid, $0.85 \mathrm{mg}$; $\mathrm{Cu}$ (as copper sulfate), $11 \mathrm{mg}$; $\mathrm{Zn}$ (as zinc sulfate), $80 \mathrm{mg}$; Mn (as manganese sulfate), $40 \mathrm{mg}$; $\mathrm{Fe}$ (as ferrous sulfate), $94 \mathrm{mg}$; I (as potassium iodide), $0.35 \mathrm{mg}$; Se (as sodium selenite), $0.35 \mathrm{mg}$; Co (as cobalt sulfate), $0.3 \mathrm{mg}$; choline chloride, $750 \mathrm{mg}$; phytase, $500 \mathrm{FTU}$
}

The pigs were weighed at the beginning (day 1 ) and end (day 14) of the feeding period to obtain bodyweight and to calculate average daily bodyweight change.

The faecal consistency was classified using a score ranking from 1 to 5 described by Pierce et al. (2005) as 1) hard firm faeces; 2) slightly soft faeces; 3) soft, partially formed faeces; 4) loose, semi-liquid faeces (diarrhoea); and 5) watery mucous-like faeces (serious diarrhoea). Faeces scores were given daily for individual pigs from day 1 until day 14. These scores were collected by a trained individual with no prior knowledge of the dietary treatment. 
At the end of the experiment, after an overnight fast, six animals (three barrows and three gilts) were selected from each treatment at random and blood samples $(10 \mathrm{~mL}$ per pig) were collected via anterior vena cava into non-heparinized vacuum tubes. These blood samples were centrifuged $\left(1200 \times \mathrm{g}, 4^{\circ} \mathrm{C}\right)$ for $10 \mathrm{~min}$ to separate serum. Serum was stored at $-20^{\circ} \mathrm{C}$ until further assays.

In the present study, serum cortisol level was determined with commercial ELISA kits (Nanjing Jiancheng Bioengineering Institute, Nanjing, China) according to the manufacturer's instructions. All samples were analysed in duplicate.

The effects of CS ingestion on the antioxidant capacities in the present study were determined by measuring antioxidant-related indices in the serum, such as the contents of total anti-oxidative capability (TAOC), enzymatic activity of catalase (CAT), total superoxide dismutase (T-SOD), copper/zinc superoxide dismutase (CuZn-SOD), glutathione peroxidase (GPx), and reduced glutathione (GSH) and malondialdehyde (MDA), using commercial assay kits according to the manufacturers' instructions (Nanjing Jiancheng Bioengineering Institute, Nanjing, China). All assays were carried out in duplicate with samples from six pigs per group. Determination of T-AOC enabled the total activities of several parameters to be evaluated, including vitamins (e.g. vitamin $C$ and vitamin E), amino acids (e.g. cysteine, methionine, tryptophan, and histidine) and metal protein (e.g. transferrin and lactoferrin), $\beta$-carotene, and GSH, all of which can convert $\mathrm{Fe}^{3+}$ to $\mathrm{Fe}^{2+}$. Then $\mathrm{Fe}^{2+}$ can be combined with phenanthroline to form stable coloured chelates. The T-AOC was measured with a spectrophotometer at $520 \mathrm{~nm}$ and expressed as activity unit $\mathrm{U} / \mathrm{mL}$ serum. In this assay, $1 \mathrm{U} \mathrm{T-AOC}$ was defined as a 0.01 increase in the absorbance value at $37^{\circ} \mathrm{Cfor} 1 \mathrm{~min}$ per $\mathrm{mL}$ serum. In the present assay, superoxide anion radicals $\left(\mathrm{O}_{2}{ }^{-}\right)$are generated by the xanthine/xanthine oxidase system, which reacts with 2-(4-iodophenyl)-3-(4-nitrophenol)-5-phenyltetrazolium chloride to form a purple formazan dye, which is used as the detector. The SOD activity was measured at $550 \mathrm{~nm}$ with a spectrophotometer and $1 \mathrm{U}$ of T-SOD activity was defined as the amount of serum capable of inhibiting the reduction of nitro blue tetrazolium by $50 \%$ of maximum inhibition. The CuZn-SOD activity was measured by adding sodium cyanide $(\mathrm{NaCN})$ to the reaction system to inactivate manganese superoxide dismutase (Mn-SOD) activity, while MnSOD was calculated by subtracting the CuZn-SOD value from T-SOD. The CAT activity was determined as the decrease in hydrogen peroxide. The enzymatic reaction of $\mathrm{H}_{2} \mathrm{O}_{2}$ degradated by CAT was terminated by the addition of ammonium molybdate, and the rest $\mathrm{H}_{2} \mathrm{O}_{2}$ combined with ammonium molybdate, generated a light-yellow complex that could be measured spectrophotometrically at $405 \mathrm{~nm}$. The CAT activity was expressed as $\mathrm{U} / \mathrm{mL}$ serum, and $1 \mathrm{U}$ of CAT activity was defined as the amount of enzyme needed to decrease $1 \mu \mathrm{mol}$ of $\mathrm{H}_{2} \mathrm{O}_{2}$ at $37^{\circ} \mathrm{C}$ for $1 \mathrm{sec}$ per $\mathrm{mL}$ serum. The GPx activity was detected by quantifying the reduction rate of reduced glutathione. The GSH reacts with 5,5-dithiobis nitrobenzoic acid to form yellow compounds. The GPx was determined with a spectrophotometer at $412 \mathrm{~nm}$ and GPx activity was expressed as $\mathrm{U} / \mathrm{mL}$ serum, in which1U of GPx was expressed as the amount that reduced the level of GSH by $1 \mu \mathrm{mol} / \mathrm{L}$ in 5 min per $0.1 \mathrm{~mL}$ serum at $37^{\circ} \mathrm{C}$. GSH can react with $55^{\prime}$-dithiobis-2-nitrobenzoic acid to produce oxidized glutathione (GSSG) and yellow chromophore 2-nitro-5-thiobenzoic acid (TNB), which can be detected at $412 \mathrm{~nm}$. GSH content was expressed as $\mathrm{mg} / \mathrm{L}$ serum. Serum MDA content was quantified using the thiobarbituric acid method, whereby MDA reacts with thiobarbituric acid in an acidic medium at $95^{\circ} \mathrm{Cfor}$ $40 \mathrm{~min}$ to form a pink coloured product. MDA was determined with a spectrophotometer at $532 \mathrm{~nm}$ and MDA was expressed as $\mathrm{nmol} / \mathrm{mL}$ serum.

The immune response status in serum was estimated by measuring the concentrations of cytokines (interleukin (IL)-1, IL-2, IL-4, IL-6, tumour necrosis factor (TNF)- $\alpha$ and $\gamma$-Interferon (IFN) and the immunoglobulins ( $\lg \mathrm{A}, \operatorname{Ig} G$ and $\lg \mathrm{M})$. These parameters were measured with the commercial porcine colorimetric ELISA kit (Nanjing Jiancheng Bioengineering Institute, Nanjing, China) according to the manufacturer's instructions. All samples were analysed in duplicate.

The experimental data generated in this study were subjected to statistical analysis with the general linear model procedure of SAS (SAS Institute Inc., Cary, NC, USA) (SAS, 2004). The one-way analysis of variance test was used to analyse all parameters. In addition, data were analysed for linear and quadratic responses to increasing dietary CS levels $(0,250,500,1000$ and $2000 \mathrm{mg} \mathrm{CS} / \mathrm{kg}$ diet) using the GLM procedure of SAS. The individual pen represented the experimental unit. All results were presented in the tables as means \pm standard error of means (SEM). Probability values of $P<0.05$ were used as the criterion for statistical significance, and $P<0.10$ was considered a tendency.

\section{Results}

As shown in Table 2, there were linear or quadratic responses in daily gain $(P<0.05, P<0.01)$ and $\mathrm{G}$ : $\mathrm{F}$ ratio $(P<0.01, P<0.01)$ to the increasing amount of $\mathrm{CS}$ inclusion during the overall experimental period (days 0 to 14$)$, with all the CS-supplemented treatments improving daily gain $(P<0.01)$ and $\mathrm{G}: \mathrm{F}$ ratio $(P$ $<0.01)$ compared with the control. However, the amount of CS in the diet had no effect $(P>0.05)$ on feed intake (ADFI) during the overall experimental period. 
There were no differences in faecal score among the treatments from days 0 to $7(P>0.05)$. There was a quadratic decrease in faecal inconsistency as the level of CS was increased from day 8 to day $14(P$ $<0.05)$ and during the overall period $(P<0.05)$ with all the CS-supplemented treatments having an improved faecal score from day 8 to day $14(P<0.05)$, and 500 and $1,000 \mathrm{mg} / \mathrm{kg}$ CS treatments improved faecal score during the overall experimental period compared with the control $(P<0.05)$.

Table 2 Effect of feeding chitosan on performance and faecal score of weaned piglets ${ }^{1}$

\begin{tabular}{|c|c|c|c|c|c|c|c|c|c|}
\hline \multirow{2}{*}{ Dietary treatment } & \multicolumn{5}{|c|}{ Chitosan levels $\mathrm{g} / \mathrm{kg}$ diet } & \multirow{2}{*}{ SEM } & \multicolumn{3}{|c|}{ Significance $^{3}$} \\
\hline & 0 (control) & 250 & 500 & 1,000 & 2,000 & & $\mathbf{T}$ & $\mathbf{L}$ & $\mathbf{Q}$ \\
\hline Initial weight, kg & 8.82 & 8.84 & 8.83 & 8.85 & 8.89 & 0.44 & ns & ns & ns \\
\hline Final weight, $\mathrm{kg}$ & 12.62 & 13.61 & 14.11 & 13.90 & 13.64 & 0.54 & ns & ns & ns \\
\hline$A D G, g / d$ & $271.4^{b}$ & $340.6^{\mathrm{a}}$ & $365.5^{\mathrm{a}}$ & $360.4^{\mathrm{a}}$ & $342.9^{\mathrm{a}}$ & 15.3 & $* *$ & * & $* *$ \\
\hline ADFI, g/d & 576.5 & 587.6 & 613.2 & 596.8 & 586.7 & 19.3 & ns & ns & ns \\
\hline G:F g/g & $0.47^{\mathrm{b}}$ & $0.58^{\mathrm{a}}$ & $0.60^{\mathrm{a}}$ & $0.60^{\mathrm{a}}$ & $0.58^{\mathrm{a}}$ & 0.03 & $* *$ & $* *$ & $* *$ \\
\hline \multicolumn{10}{|c|}{ Faecal score (days) ${ }^{2}$} \\
\hline $1-7$ & 2.74 & 2.60 & 2.34 & 2.54 & 2.49 & 0.11 & ns & ns & ns \\
\hline $8-14$ & $2.66^{\mathrm{a}}$ & $2.20^{\mathrm{b}}$ & $2.09^{b}$ & $2.03^{\mathrm{b}}$ & $2.20^{\mathrm{b}}$ & 0.12 & * & ns & * \\
\hline Overall (1-14) & $2.70^{\mathrm{a}}$ & $2.40^{\mathrm{ab}}$ & $2.21^{\mathrm{b}}$ & $2.29^{b}$ & $2.34^{\mathrm{ab}}$ & 0.10 & * & ns & * \\
\hline
\end{tabular}

SEM: standard error of mean; ADG: average daily gain; ADFI: average daily feed intake; G:F: gain per unit feed (ADG/ADFI)

Values are means of 12 pigs representing each dietary treatment

${ }^{2}$ Faecal scores were given daily for individual pigs and the average faecal score value per pig was given. This scoring system was used: 1 = hard faeces, progressing to 5 = watery mucus-like faeces

${ }^{3}$ Probability of significance: ${ }^{*} P<0.05,{ }^{\star \star} P<0.01$, ns: non-significant $(P>0.05)$.T: treatment; L: linear; Q: quadratic

${ }^{a-b}$ Means with the same superscript alphabets within rows are not significantly different $(P>0.05)$

As shown in Figure 1, serum cortisol concentration was quadratic decreased $(P<0.05)$ as the level of dietary CS was increased, and all the CS-supplemented treatments had a decreased cortisol level $(P<0.05)$.

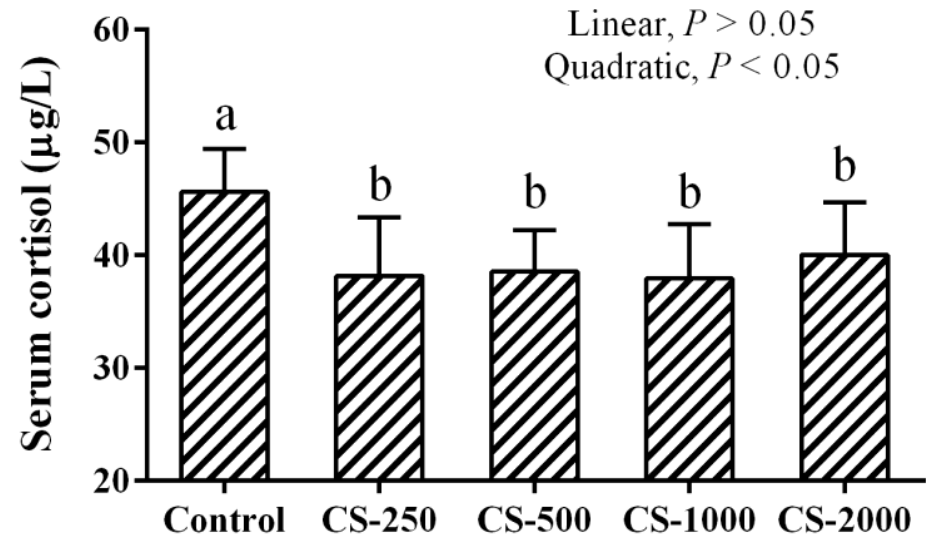

Values are means (six pigs per treatment) with standard deviations represented by vertical bars. Control: basal diet; CS250:basal diet with $250 \mathrm{mg}$ chitosan/kg; CS-500:basal diet with $500 \mathrm{mg}$ chitosan/kg; CS-1000:basal diet with1000 mg chitosan/kg; CS-2000:basal diet with 2000 mg chitosan/kg

Figure 1 Effect of feeding chitosan on serum cortisol of weaned piglets. 
As shown in Table 3, there was a quadratic increase response in activity of T-AOC $(P<0.05)$, CAT $(P$ $<0.05)$, and content of GSH $(P<0.05)$ to increased CS inclusion, with all the CS-supplemented treatments having increased serum T-AOC $(P<0.05)$ and CAT $(P<0.01)$ activities, and GSH concentration $(P<0.05)$. Meanwhile, there were quadratic increase responses in SOD (T-SOD: $P<0.01$, CuZn-SOD: $P<0.10$, MnSOD: $P<0.10)$ to the increased CS, with all the CS-supplemented treatments except for $250 \mathrm{mg} / \mathrm{kg}$ increasing serum T-SOD activity $(P<0.05)$ compared with the control. In addition, serum GPx activity was linearly $(P<0.05)$ or quadratically $(P<0.01)$ increased with increased $C S$, and all the CS-supplemented treatments except for $250 \mathrm{mg} / \mathrm{kg}$ increased GPx activity $(P<0.05)$ compared with the control. However, the concentration of serum MDA level was quadratically decreased $(P<0.05)$ with the increased amount of CS inclusion, and 500 and 2,000 mg/kg CS treatments had lower concentrations of MDA than the control.

Table 3 Effect of feeding chitosan on serum antioxidant enzymes reduced glutathione and malondialdehyde of weaned piglets ${ }^{1}$

\begin{tabular}{|c|c|c|c|c|c|c|c|c|c|}
\hline \multirow{2}{*}{ Dietary treatment } & \multicolumn{5}{|c|}{ Chitosan levels, $\mathrm{mg} / \mathrm{kg}$ diet } & \multirow{2}{*}{ SEM } & \multicolumn{3}{|c|}{ Significance $^{2}$} \\
\hline & 0 (control) & 250 & 500 & 1000 & 2000 & & $\mathbf{T}$ & $\mathbf{L}$ & $\mathbf{Q}$ \\
\hline $\begin{array}{l}\text { T-AOC, U/mL } \\
\text { SOD, U/mL }\end{array}$ & $3.07^{\mathrm{b}}$ & $3.68^{\mathrm{a}}$ & $3.81^{\mathrm{a}}$ & $3.65^{\mathrm{a}}$ & $3.68^{\mathrm{a}}$ & 0.18 & * & ns & * \\
\hline T-SOD & $101.3^{b}$ & $108.7^{\mathrm{ab}}$ & $120.2^{a}$ & $117.3^{\mathrm{a}}$ & $114.3^{\mathrm{a}}$ & 4.3 & * & ns & ** \\
\hline CuZn-SOD & 59.4 & 63.7 & 68.2 & 65.6 & 65.9 & 2.4 & ns & ns & $\S$ \\
\hline Mn-SOD & 41.8 & 45.0 & 52.0 & 51.7 & 48.4 & 3.5 & ns & ns & $\S$ \\
\hline $\mathrm{CAT}, \mathrm{U} / \mathrm{mL}$ & $2.66^{\mathrm{b}}$ & $3.79^{\mathrm{a}}$ & $3.79^{\mathrm{a}}$ & $3.48^{\mathrm{a}}$ & $3.50^{\mathrm{a}}$ & 0.21 & ** & ns & * \\
\hline $\mathrm{GPx}, \mathrm{U} / \mathrm{mL}$ & $485.3^{b}$ & $522.3^{\mathrm{ab}}$ & $548.0^{\mathrm{a}}$ & $548.0^{\mathrm{a}}$ & $543.2^{\mathrm{a}}$ & 16.3 & * & * & ** \\
\hline $\mathrm{GSH}, \mathrm{mg} / \mathrm{L}$ & $1.75^{\mathrm{b}}$ & $2.11^{\mathrm{a}}$ & $2.34^{\mathrm{a}}$ & $2.14^{\mathrm{a}}$ & $2.16^{\mathrm{a}}$ & 0.13 & * & ns & * \\
\hline $\mathrm{MDA}, \mathrm{nmol} / \mathrm{mL}$ & $3.64^{\mathrm{a}}$ & $3.24^{\mathrm{ab}}$ & $3.14^{\mathrm{b}}$ & $3.26^{\mathrm{ab}}$ & $3.17^{\mathrm{b}}$ & 0.14 & * & ns & * \\
\hline
\end{tabular}

SEM:standard error of mean; T-AOC: total antioxidant capacity; SOD: superoxide dismutase; T-SOD: total superoxide dismutase; CuZn-SOD: copper-zinc superoxide dismutase; Mn-SOD: manganese superoxide dismutase; CAT: catalase; GPx: glutathione peroxidase; GSH: reduced glutathione; MDA: malondialdehyde

${ }^{1}$ Values are means of six pigs representing each dietary treatment

2 Probability of significance: ${ }^{\star} P<0.05,{ }^{\star *} P<0.01, \S P<0.10$, ns:non-significant $(P>0.05)$. T: treatment; L: linear; $Q$ : quadratic

${ }^{a-b}$ Means with the same superscript alphabets within rows are not significantly different $(P>0.05)$

As shown in Table 4, there was a quadratic response in the concentrations of IL-1 $(P<0.05)$ and IL-2 $(P<0.05)$ to the increased CS inclusion, with $1000 \mathrm{mg} / \mathrm{kg}$ CS treatment increasing IL-1 $\beta(P<0.10)$ and IL-2 $(P<0.10)$ compared with the control. In addition, the concentration of $\lg G$ was linearly $(P<0.10)$ or quadratically $(P<0.05)$ increased with increased CS, and all CS treatments except $250 \mathrm{mg} / \mathrm{kg}$ increased $\mathrm{lgG}$ compared with the control $(P<0.05)$. No significant differences were showed in serum IL-6, IL-2, TNF- $\alpha, Y^{-}$ IFN, IgM and IgA levels $(P>0.05)$.

\section{Discussion}

Undoubtedly, the negative effects of weaning stress on growth and health in piglets are known (Kick et al., 2012; Fairbrother et al., 2005). Chitosan is a polysaccharide with non-nutritional properties, is not digested by mammalian enzymes, and is delivered to the large intestinal tract. However, numerous studies have demonstrated that CS might act as a growth promoter for farm animals. Yin et al. (2008) indicated that dietary CS $(0.025 \%)$ fed to early weaned piglets increased their performance. In agreement with those findings, the present results showed that supplementation with CS significantly increased weight gain and gain/feed of weaned piglets. The authors' previous work verified an improvement in the small intestinal morphology and digestive enzyme activities such as amylase in CS-fed piglets, which could contribute to higher nutrient digestibility (Xu et al., 2013; Xu et al., 2014). On the other hand, a higher growth performance 
inversely supported improved nutrient digestibility (Xu et al., 2014). In this study, the faecal score decreased in pigs that were fed various amounts of CS compared with the control, which may also support the improvement in performance achieved during the experiment.

Table 4 Effect of feeding chitosan on serum immune indices concentrations of weaned piglets ${ }^{1}$

\begin{tabular}{|c|c|c|c|c|c|c|c|c|c|}
\hline \multirow{2}{*}{ Dietary treatment } & \multicolumn{5}{|c|}{ Chitosan levels, mg/kg diet } & \multirow{2}{*}{ SEM } & \multicolumn{3}{|c|}{ Significance $^{2}$} \\
\hline & 0 (control) & 250 & 500 & 1,000 & 2,000 & & $\mathbf{T}$ & $\mathbf{L}$ & $\mathbf{Q}$ \\
\hline $\mathrm{IL}-1 \beta, \mathrm{ng} / \mathrm{L}$ & $167.3^{\mathrm{b}}$ & $169.5^{\mathrm{b}}$ & $174.2^{\mathrm{ab}}$ & $190.3^{a}$ & $176.8^{\mathrm{ab}}$ & 6.3 & $\S$ & ns & * \\
\hline IL-6, ng/L & 126.3 & 119.1 & 117.2 & 120.3 & 116.6 & 3.5 & ns & ns & ns \\
\hline TNF- $\alpha, n g / L$ & 161.5 & 165.7 & 160.5 & 171.9 & 164.4 & 3.8 & ns & ns & ns \\
\hline IL-2, ng/L & $149.8^{b}$ & $157.9^{\mathrm{ab}}$ & $158.3^{\mathrm{ab}}$ & $163.8^{\mathrm{a}}$ & $156.3^{\mathrm{ab}}$ & 3.6 & $\S$ & ns & * \\
\hline IL-4, ng/L & 49.2 & 52.7 & 49.5 & 49.8 & 49.5 & 1.5 & ns & ns & ns \\
\hline Y-IFN, pg/mL & 453.6 & 475.2 & 459.1 & 463.2 & 455.8 & 9.3 & ns & ns & ns \\
\hline $\operatorname{lgM}, \mu \mathrm{g} / \mathrm{mL}$ & 123.9 & 127.7 & 126.5 & 127.3 & 126.8 & 3.1 & ns & ns & ns \\
\hline $\mathrm{lg} G, \mathrm{mg} / \mathrm{mL}$ & $18.0^{\mathrm{b}}$ & $19.0^{\mathrm{ab}}$ & $19.9^{a}$ & $20.0^{\mathrm{a}}$ & $19.6^{\mathrm{a}}$ & 0.5 & * & $\S$ & * \\
\hline $\lg A, \mu g / m L$ & 64.1 & 65.2 & 66.5 & 66.8 & 65.5 & 2.4 & ns & ns & ns \\
\hline
\end{tabular}

SEM:standard error of mean

${ }^{1}$ Values are means of six pigs representing each dietary treatment

${ }^{2}$ Probability of significance: ${ }^{\star} P<0.05,{ }^{\star *} P<0.01, \S P<0.10$, ns: non-significant $(P>0.05)$. T: treatment; L: linear; Q: quadratic

${ }^{a-b}$ Means with the same superscript alphabets within rows are not significantly different $(P>0.05)$

Cortisol is the main active hormone of the hypothalamic-pituitary-adrenal (HPA) axis in pigs. This is a cholesterol-derived steroid that is synthesized in the fascicular zone of the adrenal cortex under the control of the pituitary adrenocorticotropic hormone. Cortisol has proteolytic and lipolytic activity in the peripheral tissues and gluconeogenesis and protein synthesis activity in the liver (McMahon et al., 1988). The HPA axis in pigs is exquisitely sensitive to endogenous and exogenous stimuli, both acute and chronic. It is therefore a valuable index for monitoring stress conditions of farm animals (Mormède et al., 2007). An elevation of cortisol illustrates the activation of HPA axis. The current experiment showed that the content of cortisol decreased significantly in piglets fed CS, which suggested that CS could alleviate stress in piglets.

Molecular oxygen is essential for the survival of all aerobic organisms. $\mathrm{O}_{2}$ serves as the final electron acceptor in the process of aerobic energy metabolism, and reduces to $\mathrm{H}_{2} \mathrm{O}$ by mitochondrial enzymes in the cell. However, partially reduced and highly reactive metabolites of $\mathrm{O}_{2}$ may be formed when organisms suffer from endogenous and exogenous stimulation, to produce superoxide anion $\left(\mathrm{O}_{2^{-}}\right)$and hydrogen peroxide $\left(\mathrm{H}_{2} \mathrm{O}_{2}\right)$. These derivatives of oxygen (reactive oxygen species, e.g. $\mathrm{O}_{2}-$ and $\mathrm{H}_{2} \mathrm{O}_{2}$ ) are highly reactive and toxic, and can lead to increased oxidative stress in a variety of tissues (Rao \& Berk, 1992). Oxidative stress can damage biomolecules, including cellular lipids, proteins, amino acids, and deoxyribonucleic acid, thereby inhibiting their normal function (Fang et al., 2002; Valko et al., 2007). For piglets, many endogenous and exogenous factors, such as environmental factors, weaning, biting, ranking, disease, and infection, can induce oxidative stress, resulting in poor growth performance.

Malondialdehyde is the most familiar breakdown product of lipid peroxidation, and its level is frequently used as a main marker to scale the extent of lipid oxidative damage caused by ROS. The authors observed that CS supplementation can decrease serum MDA content in weaned pigs, suggesting that CS could depress their lipid peroxidation. The scavenging capacity of free radicals is related to the nonenzymatic and enzymatic antioxidant defence systems, which were determined to further identify the manner of inhibition of oxidative damage by CS. Antioxidant enzymes are essential key factors against oxidative stress induced by stimulus factors in animal defence system.

The enzyme defence system consists of SOD, CAT and GPx. SOD provides the efficient dismutation of superoxide radicals $\left(\mathrm{O}_{2}-\right)$ into less toxic $\mathrm{H}_{2} \mathrm{O}_{2}$, while CAT and $\mathrm{GPx}$ reduce $\mathrm{H}_{2} \mathrm{O}_{2}$ to $\mathrm{O}_{2}$ and $\mathrm{H}_{2} \mathrm{O}(\mathrm{Ahmad}$ et al., 2012). Indeed, CS has shown beneficial effects on relieving oxidative stress induced by certain drugs or 
under various physiological and pathophysiological conditions (Jeon et al., 2003; Anandan et al., 2013; Ramasamy et al., 2014). Ramasamy et al. (2014) reported that dietary supplementation with $200 \mathrm{mg} \mathrm{CS} / \mathrm{kg}$ body weight per day for seven weeks, along with $\mathrm{CCl} 4$, markedly increased hepatic and circulatory SOD, CAT, GPx levels in rats. Additionally, Jeon et al. (2003) concluded that CS significantly increased hepatic CAT and SOD activities in chronic hepatic injuries in rats that had been induced by carbon tetrachloride. In addition, previous studies undertaken in the authors' laboratory showed that supplementation of CS in diets resulted in improvement in serum GPx, SOD and CAT activities in piglets (Li et al., 2013) and serum SOD activity in beef cattle ( $\mathrm{Li}$ et al., 2015). In agreement with those findings, the current results showed that dietary supplementation with CS increased serum SOD, GPx, and CAT activities, which are representative enzymatic antioxidants in the body.

The GSH is an important major non-enzymatic antioxidant in cells. Reduction of GSH could converse to oxidized GSH (GSSG) spontaneously or by enzymatic catalysis to trap radical species (Ghezzi, 2005). In the current study, dietary CS increased GSH content in the serum of pigs, which was comparable with the study of Ramasamy et al. (2014), which reported that dietary supplementation with CS resulted in higher GSH content in the livers of rats with hepatic injury induced by tetrachloride. Further, Anandan et al. (2013) reported that CS could have increased effects on the GSH level in the heart tissue of aged rats. This illustrates that CS as antioxidant could improve resistance to oxidation as measured by increased GSH content in serum.

The T-AOC, which includes a number of antioxidant enzymes and related biomolecules that can remove free radicals from a specific organ or living organism, reflects the total antioxidant ability. Limited published reports to date have shown that CS increased significantly the total antioxidant capacity of livestock. Obvious results in this study were observed in T-AOC level, while animals supplemented with CS also showed a dose-dependent effect. Thus, these results show that CS strengthened the oxidative defence mechanisms.

These combined findings suggest that CS might help to protect weaned pigs against oxidative stress, as they appear to reduce lipid peroxidation and improve their antioxidant defence systems functions in vivo.

With regard to the serum production of cytokines and immunoglobulins, which were used as further understanding of immune system status, the current study measured the concentrations of cytokines and immunoglobulins in serum. ILs are a group of cytokines that play an important role in the immune system. Among these, IL-1 $\beta$ mediates the immune response by i) promoting the proliferation and differentiation of thymocytes and mature T-cells; ii) enhancing B-cell differentiation; iii) inhibiting the growth of tumour cells and killing them; and (iv) inducing T-cells to generate IL-2 (Yin et al., 2008). In addition, IL-2 is a key cytokine with broad spectrum crucial immunomodulatory activities. In the present study, CS was shown to increase the production of serum IL-1 $\beta$ and IL-2 in piglets. Similar to the current findings, Yin et al. (2008) demonstrated that CS supplementation could promote the generation of IL-1 $\beta$ of early-weaned piglet, since the increases in ILs indicate the activation of an immune reaction that might lead an improvement in immune status. Immunoglobulins are proteins with antibody activity that exist mainly in the plasma and are used to promote phagocytosis of monocytes and macrophages, and identify and neutralize bacteria and viruses (Litman et al., 1993). Serum IgG is the most persistent and important antibody in the primary immune response, and is used to promote phagocytosis of monocytes and macrophages, neutralize the toxicity of bacterial toxins, and combine with viral antigens to prevent the virus infecting host cells. Here, the authors reported that serum IgG level was increased markedly in CS supplemented pigs, indicating that CS efficiently modulated a humoral immune response, which may provide an advantage in increasing weaned pig immunity to prevent susceptibility to disease and enhance resistance to infections. The nitric oxide and arachidonic acid pathways were regulated by chitosan in a dose-dependent relationship may be reasons that chitosan affected the immune function in weaned piglets (Li et al., 2015; Li et al., 2017). All these results support the immunostimulatory effects of CS, which may be the reason for improved performance.

\section{Conclusion}

In conclusion, the results observed in this study showed that the use of a CS-supplemented diet may be effective in improving anti-oxidant and free radical scavenging capacity and regulating the immunological response of post-weaning piglets, and limiting the negative effects of weaning on growth performance in piglets.

\section{Acknowledgements}

This study was supported by a grant from the National Natural Science Foundation of China (No. 31460605). The author thanks their laboratory colleagues Y.L. Wang and P.F. Zhang for their assistance in the data and sample collection, and laboratory analysis. 


\section{Authors' Contributions}

BLS and SMY designed this experiment. YQX, ZQ and ZQW performed the animal experiment, measured and acquired the data, and participated in results and statistics. YQX and ZQW wrote the manuscript and revised it. BLS and SMY supervised all processes through performing the experiment to writing the manuscript. All authors read and approved the final manuscript.

\section{Conflict of Interest Declaration}

The authors certify that there is no potential conflict of interest to disclose.

\section{References}

Ahmad, H., Tian, J., Wang, J., Khan, M.A., Wang, Y., Zhang, L.\& Wang, T., 2012. Effects of dietary sodium selenite and selenium yeast on antioxidant enzyme activities and oxidative stability of chicken breast meat. J. Agric. Food Chem. 60, 7111-7120.

Anandan, R., Ganesan, B., Obulesu, T., Mathew, S., Asha, K.K., Lakshmanan, P.T. \& Zynudheen, A.A., 2013. Antiaging effect of dietary chitosan supplementation on glutathione-dependent antioxidant system in young and aged rats. Cell Stress Chaperones. 18, 121-125.

Dash, M., Chiellini, F., Ottenbrite, R.M. \& Chiellini, E., 2011. Chitosan-A versatile semi-synthetic polymer in biomedical applications. Prog. Polym. Sci. 36, 981-1014.

Fairbrother, J.M., Nadeau, E. \& Gyles, C.L., 2005. Escherichia coli in postweaning diarrhea in pigs: an update on bacterial types, pathogenesis, and prevention strategies. Anim. Health Res. Rev. 6, 17-39.

Fang, Y.Z., Yang, S. \& Wu, G., 2002. Free radicals, antioxidants, and nutrition. Nutrition18, 872-879.

Ghezzi, P., 2005. Regulation of protein function by glutathionylation. Free Radic. Res. 39, 573-580.

Jayakumar, R., Menon, D., Koyakutty, M., Nair, S.V. \& Tamura, H., 2010. Biomedical applications of chitin and chitosan based nanomaterials-A short review. Carbohydr. Polym. 82, 227-232.

Jeon, T.I., Hwang, S.G., Park, N.G., Jung, Y.R., Shin, S.I., Choi, S.D. \& Park, D.K., 2003. Antioxidative effect of chitosan on chronic carbon tetrachloride induced hepatic injury in rats. Toxicology 187, 67-73.

Kick, A.R., Tompkins, M.B., Flowers, W.L., Whisnant, C.S. \& Almond, G.W., 2012. Effects of stress associated with weaning on the adaptive immune system in pigs. J. Anim. Sci. 90, 649-656.

Kim, K.W. \& Thomas, R.L., 2007. Antioxidative activity of chitosans with varying molecular weights. Food Chem. 101, 308-313.

Li, J.L., Shi, B.L., Yan, S.M., Jin, L., Li, T.Y., Xu, Y.Q. \& Guo, Y.W., 2013. Effects of dietary supplementation of chitosan on stress hormones and antioxidative enzymes in weaned piglets. J. Anim. Vet. Adv. 12, 650-654.

Li, J.L., Xu, Y.Q., Shi, B.L., Sun, D.S., Yan, S.M. \& Guo, X.Y., 2017. Dietary chitosan affects metabolism of arachidonic acid in weaned piglets. Czech J. Anim. Sci. 62, 58-66.

Li, J., Shi, B., Yan, S., Jin, L., Guo, Y. \& Li, T., 2015. Effects of chitosan on nitric oxide production and inducible nitric oxide synthase activity and mRNA expression in weaned piglets. Czech J. Anim. Sci. 60, 359-366.

Li, T., Na, R., Yu, P., Shi, B.L., Yan, S.M., Zhao, Y.G. \& Xu, Y.Q., 2015. Effects of dietary supplementation of chitosan on immune and antioxidative function in beef cattle. Czech J. Anim. Sci. 60, 38-44.

Litman, G.W., Rast, J.P., Shamblott, M.J., Haire, R.N., Hulst, M., Roess, W., Litman, R.T., Hinds-Frey, K.R., Zilch, A. \& Amemiya, C.T., 1993. Phylogenetic diversification of immunoglobulin genes and the antibody repertoire. Mol. Biol. Evol. 10, 60-72.

Liu, J., Zhang, J. \& Xia, W., 2008. Hypocholesterolaemic effects of different chitosan samples in vitro and in vivo. Food Chem. 107, 419-425.

Madec, F., Bridoux, N., Bounaix, S., Cariolet, R., Duval-Iflah, Y., Hampson, D.J. \& Jestin, A., 2000. Experimental models of porcine post-weaning colibacillosis and their relationship to post-weaning diarrhoea and digestive disorders as encountered in the field. Vet. Microbiol. 72, 295-310.

McMahon, M., Gerich, J. \&Rizza, R., 1988. Effects of glucocorticoids on carbohydrate metabolism. Diabetes Metab. Rev. 4, 17-30.

Mormède, P., Andanson, S., Aupérin, B., Beerda, B., Guémené, D., Malmkvist, J., Manteca, X., Manteuffel, G., Prunet, P., Van Reenen, C.G., Richard, S. \& Veissier, I., 2007. Exploration of the hypothalamic-pituitary-adrenal function as a tool to evaluate animal welfare. Physiol. Behav. 92, 317-339.

NRC. 2012. Nutrient requirements of swine. 11th ed. National Academy Press, Washington DC

Park, S.H., Dutta, N.K., Baek, M.W., Kim, D.J, Na, Y.R., Seok, S.H., Lee, B.H., Cho, J.E., Cho, G.S. \& Park, J.H., 2009. $\mathrm{NaCl}$ plus chitosan as a dietary salt to prevent the development of hypertension in spontaneously hypertensive rats. J. Vet. Sci. 10, 141-146.

Pierce, K.M., Callan, J.J., McCarthy, P., \& O'Doherty, J.V., 2005. Performance of weanling pigs offered low or high lactose diets supplemented with avilamycin or inulin. Anim. Sci. 80, 313-318.

Qin, C., Du, Y., Xiao, L., Li, Z. \& Gao, X., 2002. Enzymic preparation of water-soluble chitosan and their antitumor activity. Int. J. Biol. Macromol. 31, 111-117.

Ramasamy, P., Subhapradha, N., Shanmugam, V. \& Shanmugam, A., 2014. Protective effect of chitosan from Sepia kobiensis (Hoyle 1885) cuttlebone against CCl4 induced hepatic injury. Int. J. Biol. Macromol. 65, 559-563.

Rao, G.N., \& Berk, B.C., 1992. Active oxygen species stimulate vascular smooth muscle cell growth and protooncogene expression. Circ. Res. 70, 593-599.

Valko, M., Leibfritz, D., Moncol, J., Cronin, M.T., Mazur, M. \& Telser, J., 2007. Free radicals and antioxidants in normal physiological functions and human disease. Int. J. Biochem. Cell Biol. 39, 44-84.

Villiers, C., Chevallet, M., Diemer, H., Couderc, R., Freitas, H., Van Dorsselaer, A., Marche, P.N. \& Rabilloud, T., 2009. 
From secretome analysis to immunology chitosan induces major alterations in the activation of dendritic cells via a TLR-4 dependent mechanism. Mol. Cell Proteomics.8, 1252-1264.

Walsh, A.M., Sweeney, T., Bahar, B. \& O'Doherty, J.V., 2013. Multi-functional roles of chitosan as a potential protective agent against obesity. PLOS One, 8, e53828.

Wijtten, P.J.A., van der Meulen, J. \& Verstegen, M.W.A., 2011. Intestinal barrier function and absorption in pigs after weaning: A review. Br. J. Nutr. 105, 967-981.

Xu, Y.Q., Shi, B.L., Yan, S.M., Li, T.Y., Guo, Y.W. \& Li, J.L., 2013. Effects of chitosan on body weight gain, growth hormone and intestinal morphology in weaned pigs. Asian-Australas. J. Anim. Sci. 26, 1484-1489.

Xu, Y., Shi, B., Yan, S., Li, J., Li, T., Guo, Y. \& Guo, X., 2014. Effects of chitosan supplementation on the growth performance, nutrient digestibility, and digestive enzyme activity in weaned pigs. Czech J. Anim. Sci. 59, $156-163$.

Yin, Y.L., Tang, Z.R., Sun, Z.H., Liu, Z.Q., Li, T.J., Huang, R.L., Ruan, Z., Deng, Z.Y., Gao, B. \& Chen, L.X., 2008. Effect of galacto-mannan-oligosaccharides or chitosan supplementation on cytoimmunity and humoral immunity in early weaned piglets. Asian-Australas. J. Anim. Sci. 21, 723-731.

Zaharoff, D.A., Rogers, C.J., Hance, K.W., Schlom, J. \& Greiner, J.W., 2007. Chitosan solution enhances both humoral and cell-mediated immune responses to subcutaneous vaccination. Vaccine 25, 2085-2094.

Zheng, L.Y. \& Zhu, J.F., 2003. Study on antimicrobial activity of chitosan with different molecular weights. Carbohyd. Polym. 54, 527-530.

Zhu, L.H., Zhao, K.L., Chen, X.L. \& Xu, J.X., 2012. Impact of weaning and an antioxidant blend on intestinal barrier function and antioxidant status in pigs. J. Anim. Sci.90, 2581-2589. 